\title{
Career intentions and choices of paediatricians entering training in the UK
}

\author{
David Shortland, ${ }^{1}$ Damian Roland, ${ }^{2,3}$ Daniel Edward Lumsden, ${ }^{4}$ Carol Ewing, ${ }^{5}$ \\ Veline L'Esperance, ${ }^{6}$ Martin McColgan, ${ }^{7}$ Rachel Winch, ${ }^{7}$ Shazia Mahmood ${ }^{7}$
}

\begin{abstract}
${ }^{1}$ Poole Hospital NHS Trust, Poole Hospital, Poole, UK ${ }^{2}$ SAPPHIRE, Health Sciences, University of Leicester, Leicester, UK

${ }^{3}$ Paediatric Emergency

Medicine Leicester Academic (PEMLA) Group, Leicester Royal Infirmary, Leicester, UK ${ }^{4}$ Evelina Children's Hospital, London, UK

${ }^{5}$ Royal Manchester Children's Hospital, Manchester, UK ${ }^{6}$ King's College London, London, UK

${ }^{7}$ Royal College of Paediatrics and Child Health, London, UK
\end{abstract}

\section{Correspondence to}

Dr David Shortland, Poole Hospital NHS Trust, Poole Hospital, Longfleet Road, Poole, Dorset BH15 2JB, UK; david.shortland@poole.nhs.uk

Received 28 April 2014 Revised 4 December 2014 Accepted 5 December 2014 Published Online First 23 December 2014

\section{ABSTRACT}

Introduction The paediatric workforce has grown substantially in recent years. Roles have changed considerably with the introduction of working time legislation and a move towards a trained doctor solution. By gaining a better understanding of paediatric trainees' career intentions, this study aims to assess whether the right workforce is being trained to meet the future demand for paediatric services in the UK.

Method A survey was sent to paediatric specialist trainees, when they were expected to have completed their 1st year of Specialty Training or Fixed Term Specialty Training Appointments, in 2009 (part 1). A second survey was sent to the same cohort when they were expected to have completed their $3 r d$ year in 2011 (part 2).

Results In part 1 of the survey, the response rate was $79.1 \%$. In part 2 the response rate was $80.5 \%$. Of those who had responded to part $1,87.4 \%$ also responded to part 2. The attrition rate of trainees leaving the paediatric training scheme between the 1st year and 3rd year of training was $15 \%$. Of those still training in paediatrics after the $3 r d$ year, $38.7 \%$ intended to be subspecialty paediatricians, $25.7 \%$ general paediatricians, $5.4 \%$ community paediatricians and $3.5 \%$ academic paediatricians. $26 \%$ were undecided and $0.6 \%$ did not intend to follow a career in paediatrics at all. The proportion of trainees who were undecided about their career intentions had risen substantially from $7.7 \%$ after the 1st year. There was a decrease in trainees' confidence in obtaining a consultant post between the 1st year and the 3rd year.

Conclusions Workforce planning is a complex task and this study shows that trainees will change their career plans while progressing through their run-through programmes. A better understanding of these factors will enable the Royal College of Paediatrics and Chld Health to deliver the right workforce for the UK.

\section{INTRODUCTION}

Historically, the National Health Service (NHS) delivered acute services through trainees working very long hours. ${ }^{1}$ In many of the more demanding specialties trainees would have worked 1 in 2 on-call rotas in the 1970 s and 1 in 3 rotas in the 1980s.

CrossMark

To cite: Shortland $D$,

Roland D, Lumsden DE,

et al. Arch Dis Child

2015:100:537-541.
In the 1990 s a unified registrar grade was introduced. ${ }^{2}$ At around the same time the 'New Deal' was introduced which, for the first time, created a financial disincentive for hospitals to have rotas where trainees worked excessively long shifts and weekly hours. ${ }^{3}$ In 1998 the Council of the European Parliament agreed the principle of the

\section{What is already known on this topic?}

- There have been previous studies on the medical workforce but none that has looked at paediatric trainees in such detail.

- This study has looked at a cohort of trainees to study their career aspirations, the concerns they have about their training and, where appropriate, why they have given up the training in paediatrics.

\section{What the study adds?}

- This is the first cohort study specifically of paediatric trainees in the UK and shows significant changes to their career aspirations at an early stage after entering training.

- There is a significant attrition rate in the first 3 years of entering paediatric training, with a high proportion of trainees unsure as to how they would like to practice within the paediatric specialty and an imbalance between trainees' desire to practice within a subspecialty and the requirements of the service.

- The study shows how difficult it is to plan for the future paediatric workforce.

legislation for the European Working Time Directive which through health and safety legislation, would reduce the average number of hours which doctors in training could be expected to work each week. ${ }^{34}$

In 2005 there were further changes to medical training with the introduction of Modernising Medical Careers (MMC). ${ }^{5}$ This programme replaced the traditional medical grades of House Officer, Senior House Officer and Registrar with the grade of specialty trainee. MMC offered some advantages for medical trainees as they had more career security and worked within a geographically defined location. However, trainees had to choose their preferred specialty at a relatively early stage in their career. ${ }^{6}$ Although there has always been attrition in medical specialties as training progresses, ${ }^{7}$ the effect of choosing a final career early in training is not known.

Historically career opportunities have been relatively good for those completing their training as there has been a considerable expansion in the number of general practitioner and consultant posts in recent years. Between 2001 and 2011 there was 
a $51.6 \%$ increase of consultants and a $25 \%$ increase in the number of General Practitioners (GPs). ${ }^{8}$ Reforms in healthcare and doctors' working practices have, however, required a reassessment of medical workforce numbers. ${ }^{9} 10$

There have been previous cohort studies of medical graduates assessing career choices at the time of graduation and throughout the training period. ${ }^{11-16}$ These studies compared preferences with actual career post obtained, and examined factors causing these choices. However, few have focused on paediatric training in the UK. ${ }^{11}$

To inform workforce planning and to obtain a better understanding of paediatric trainees' career intentions, the Royal College of Paediatrics and Chld Health (RCPCH) sent a questionnaire to the cohort group of all 1st year of paediatric specialty training (ST1) and Fixed Term Specialty Training Appointments 1 trainees who began training in paediatrics in 2007.

\section{METHODOLOGY}

The initial survey, part 1 was sent out using SurveyMonkey shortly after the cohort completed their ST1 year with the intention of following the cohort through the entirety of their training. Trainees' email addresses were gathered from the RCPCH membership database and training records.

Part 2 of the cohort included all respondents and nonrespondents to part 1 and was sent using a further SurveyMonkey questionnaire following the cohort's 3rd year of training in October 2010. For those trainee doctors who had left paediatrics and were willing to be contacted, an in-depth telephone interview was carried out between November 2011 and January 2012 to determine the reasons for leaving paediatrics.

\section{RESULTS}

Of the 440 STs and Fixed Term Specialty Training Appointments who were contacted for the first part of this study, 352 responses were received $(80.0 \%)$. For the second part, 354 of 440 responses were received $(80.5 \%)$.

Table 1 shows the reasons given by respondents for choosing paediatrics. Personal attributes suitable to paediatrics was cited as the most common reason for choosing paediatrics.

Table 1 Trainees' reasons for choosing paediatrics as a career choice, part 1

\begin{tabular}{lcc}
\hline Reason & No & $\begin{array}{l}\text { Percentage of } \\
\text { respondents }\end{array}$ \\
\hline You regard your personal attributes more & 216 & 73.5 \\
suitable to paediatrics & 206 & 70.1 \\
Rewarding & 204 & 69.4 \\
Enjoyed it as an undergraduate & 171 & 58.2 \\
Enjoyed it in foundation & 118 & 40.1 \\
Academically satisfying & 79 & 26.9 \\
Inspired by a role model & 74 & 25.2 \\
Previous work in paediatrics (UK or overseas) & 73 & 24.8 \\
Elective in paediatrics & 24 & 8.2 \\
Offers good work-life balance & 14 & 4.8 \\
Parental/peer influence & 12 & 4.1 \\
Financial prospects & 12 & 4.1 \\
Has a favourable competition ratio & 52 & 17.7 \\
Other & & \\
\hline
\end{tabular}

Of the 294 ST trainees who responded to part 1, $82(28 \%)$ listed 131 reservations about choosing paediatrics as a specialty (1.59 per doctor). The two most common reasons cited were poor work life balance and intense on-call commitments (table 2).

In the 1 st year of this study $24.4 \%$ of the cohort intended to become a paediatric subspecialist. This compares with the $35.3 \%$ of consultant paediatricians (excluding academic subspecialists) recorded as subspecialists in a tertiary centre or specialists in a district general hospital or working within a network in the 2011 RCPCH census. Figure 1 shows a comparison between the 2011 paediatric workforce and the career intentions of those surveyed in this study. Of those intending to be a subspecialist paediatrician, the three most popular were neonatology (35.4\%) paediatric cardiology (14.6\%) and oncology $(9.8 \%)$. The most popular subspecialty interests among trainees who intended to become general paediatricians were paediatric cardiology, infectious disease, allergy and immunology, and respiratory medicine.

After 3 years there had been a marked increase in the number of trainees intending to pursue subspecialist training $(38.7 \%$ compared with $24.4 \%$ at ST1). The number of trainees intending to work in community paediatrics had fallen from $6.8 \%$ after 1 year to $5.4 \%$ after 3 years. Those intending to pursue a career in academic medicine had fallen to $3.5 \%$ by year 3 from $5.1 \%$ after 1 year. A chi-square test using the part 1 and part 2 cohorts as variables shows that the stage of training career and career intention are related. There were a higher number of trainees after 3 years intending to train in a subspecialty; $38.7 \%$ compared with $35.3 \%$ of the workforce as recorded in the RCPCH 2011 census. There was an apparent 14.6\% shortfall in those intending to be general paediatricians and a $14.5 \%$ shortfall in those intending to be community paediatricians. However, as $26.0 \%$ of the part 2 cohort was undecided about its career intentions, results should be treated with caution. This is shown in table 3 .

There had been a large increase in trainees preferring to work in subspecialty areas between the 1 st year and 3rd year of this survey. After 3 years, the three most attractive subspecialties

Table 2 Paediatric specialty trainees in part 1: reservations about choosing paediatrics

\begin{tabular}{lcl}
\hline Reservation type & $\begin{array}{l}\text { Number of } \\
\text { reservations }\end{array}$ & $\begin{array}{l}\text { Percentage of } \\
\text { reservation }\end{array}$ \\
\hline Work-life balance & 37 & 28.2 \\
On-call commitment & 18 & 13.7 \\
Limited experience & 14 & 10.7 \\
Length of training & 9 & 6.9 \\
Limited hours & 9 & 6.9 \\
Workload & 9 & 6.9 \\
Other interest & 8 & 6.1 \\
Need to move posts & 7 & 5.3 \\
Emotional & 5 & 3.8 \\
Rota problems & 4 & 3.1 \\
High responsibility & 3 & 2.3 \\
Availability of posts & 2 & 1.5 \\
Financial & 2 & 1.5 \\
Challenging & 1 & 0.8 \\
Senior driven & 1 & 0.8 \\
Unsociable specialty & 1 & 0.8 \\
Unsuccessful in applying & 1 & 0.8 \\
Total & 131 & \\
\hline
\end{tabular}




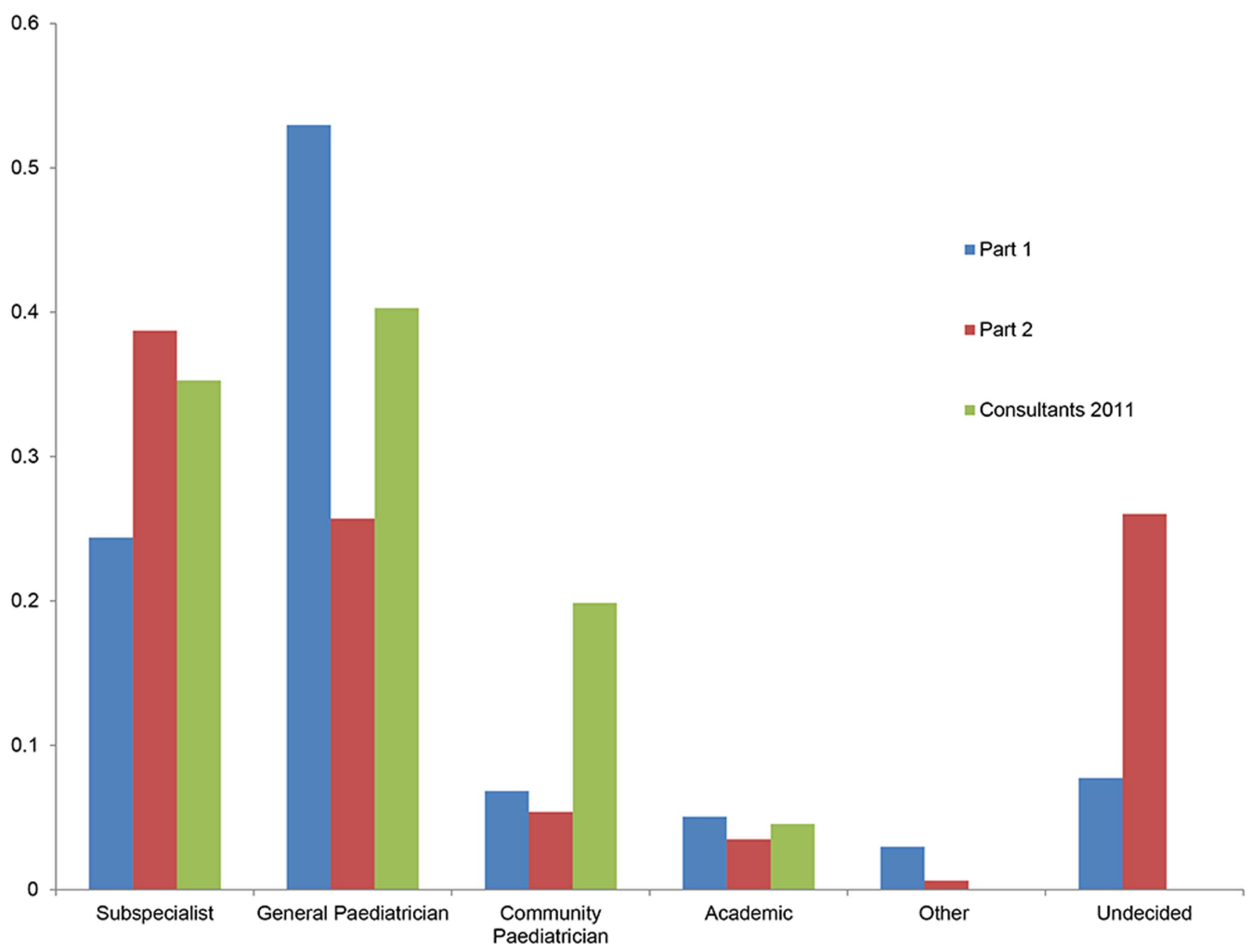

Figure 1 Comparison of part 1 and part 2 career intentions with 2011 consultant job types.

remained neonatology $(29.5 \%)$, oncology $(9.8 \%)$ and paediatric cardiology (9\%).

In part 1 of the study, $76.7 \%$ of trainees were confident or reasonably confident about obtaining their chosen consultant post while $22.5 \%$ were not confident.

The proportion of trainees confident of obtaining their preferred consultant post fell slightly from $12.3 \%$ in the 1 st year of the survey to $11.5 \%$ in the $3 \mathrm{rd}$ year. The proportion of those reasonably confident between the 1 st year and $3 \mathrm{rd}$ year fell by $6.2 \%(64.4 \%$ to $58.2 \%)$. There was a rise of $7 \%$ stating that they were not confident of obtaining their chosen post between the 1 st year and 3 rd year. The most common reasons given were; lack of available consultant posts, competition for grid training posts and concerns that they would not complete training.

Table 3 How career intentions in part 2 match the current workforce

\begin{tabular}{lll}
\hline & Part 2 cohort & Consultants 2011 \\
\hline General & 81 & 1377 \\
Community & $25.7 \%$ & $40.3 \%$ \\
& 17 & 679 \\
Subspecialty & $5.4 \%$ & $19.9 \%$ \\
& 122 & 1206 \\
Academic & $38.7 \%$ & $35.3 \%$ \\
& 11 & 156 \\
Other & $3.5 \%$ & $4.6 \%$ \\
& 2 & 0 \\
Undecided & $0.6 \%$ & \\
& 82 & 0 \\
Total & $26.0 \%$ & 3418 \\
\hline
\end{tabular}

The total attrition rate for paediatric trainees leaving the specialty over the first 3 years of their training was $15 \%$. Of the cohort $4 \%$ continued to work in paediatrics but no longer in training posts and $11 \%$ decided to train in another specialty or pursue another career. Of those no longer undertaking paediatric training, $51.3 \%$ were pursuing a career in general practice.

In order to be able to understand the reasons why trainees left paediatrics we conducted a telephone interview with 15 respondents who had stated in the survey that they were no longer in paediatric training. Four were in paediatric related clinical training programmes, seven were in non-paediatric related clinical related programmes and four no longer in training. Four trainees had left in ST1, four in ST2, six in ST3 and one in ST4. Of those leaving the specialty $71 \%$ were male and $29 \%$ were female. The average length of completed training was 27 months. The average length of time between deciding to leave paediatrics and no longer working in specialty was 6.8 months.

Table 4 What interested you in your new specialty?

\begin{tabular}{lc}
\hline & Count \\
\hline Better work/life balance & 4 \\
Broader experience/more variety & 3 \\
Holistic approach to patient treatment & 2 \\
General paediatrics too focused on primary care provision & 2 \\
Research & 2 \\
Less focus on service provision & 1 \\
Paediatric training interested me in that specialty & 1 \\
Supervision & 1 \\
Positive role models & 1 \\
More professional development opportunities & 1 \\
Total & $18^{*}$ \\
\hline${ }^{*}$ Note that respondents could provide more than one answer.
\end{tabular}


The most common reason for the decision to leave was that training in another specialty seemed to be more attractive than continuing in paediatrics. Trainees most often stated that different specialties have a better work-life balance, more variety of work and a more holistic approach to patient care (table 4). The most commonly expressed reservations about paediatrics were rota intensity, staffing pressures, reluctance to continue to work in neonatology and on-call commitments. On a positive note, all 15 respondents said that they would recommend paediatrics to other doctors intending to train in this specialty.

After 3 years, 91.1\% intend to be a consultant and 2.9\% intend to be a specialty doctor. The remainder were either unsure or did not express an intent. The ratio of male to female trainees intending to be consultants is approximately equal to the overall gender ratio at $25.1-74.9 \%$.

\section{DISCUSSION}

This study has shown that trainees choose paediatrics because they believe their personal attributes are most suited to it and they find it a rewarding area of medicine. However, there are strong reservations about work-life balance and on-call commitments. The job type intentions (ie, generalist, specialist, community paediatrician) are not in line with the current consultant workforce. The number intending to be subspecialists increased during the study. Confidence in obtaining their preferred consultant position is not high and 15\% of the cohort has left training in the first 3 years, with over half of those who are no longer undertaking paediatric training pursuing a career in general practice.

Understanding the trainees' reasons for choosing a particular specialty is very important; trainees are now expected to commit to their ultimate career choice at an earlier career stage than previously, usually around halfway through foundation training. This is compounded by a loss of flexibility to change between career choices as a trainee experiences different specialties.

Thomas ${ }^{12}$ concluded that doctors commit to their specialty at three defined stages. First, there are those, largely comprising of surgeons that commit early. There are a group who commit over time, and this group mostly chose their career between the 1st year and 3rd year after graduating. The third group commit late and decide their ultimate career choice at a later stage. While the evidence would suggest that medical students positively choose a career, it is also possible that their decision is influenced by the perceived likelihood of obtaining a chosen training post; whether the specialty offers run-through or uncoupled training, and their perception of how likely they are to successfully complete training. The British Medical Association study ${ }^{16}$ showed that, at graduation, less than $20 \%$ of the cohort was confident that they would automatically get a job once they had completed their training and less than $10 \%$ were confident that they would get a job in their chosen specialty.

Since 1928, when a record of the number of consultants in the UK was first collected by the British Paediatric Association, there has been a $6000 \%$ increase in the number of paediatricians. However paediatrics is not a single specialty; there are 17 recognised subspecialties. Historically, trainees have had relatively few problems in obtaining substantive posts in paediatrics and a high likelihood of working within the subspecialty of their choice. Until the beginning of the 1990s junior doctors had effectively two career choices; either as a general practitioner or a consultant. While there have been other grades of doctors (eg, clinical medical officers, senior clinical medical officers and associate specialists) traditionally doctors did not choose these posts in the early part of their career.
Previous surveys have suggested that junior doctors chose a specialty that they are positively attracted to and this is also evident in the first part of this cohort study- $73 \%$ of respondents choosing paediatrics because they felt their personal attributes were most suited to this specialty, $70 \%$ choosing it because it was rewarding and $69 \%$ because they had enjoyed it as an undergraduate. The majority of paediatric trainees train to be consultants and intend to apply for this grade on gaining their Certificate of Completed Training.

There are currently two drivers that could have a significant effect on the shape of the future paediatric workforce. The first is the current economic climate in which it is becoming increasingly difficult to expand consultant numbers, particularly if there are no issues around working time legislation and the delivery of safe patient care. The second is the significant increase in the number of paediatric trainees over the past 10 years. Where there is no increase in consultant growth rate, there would need to be a reduction in the current ratio of trainees to consultants. The actual number would vary slightly depending on the proportion of consultants intending to work part-time. In 2011 there were 3878 registered paediatric trainees and 3418 consultants. The ratio for paediatrics was, therefore, 1 trainee to 0.88 consultants. One of the rationales for the change to the MMC training programme was that it would align training numbers with future consultant workforce requirements.

This survey also highlighted the large increase in trainees preferring to work in subspecialty areas between the 1st year and 3 rd year of the study. This is likely to reflect the increasing exposure of our trainees to these aspects of the specialty. It is, however, important that these aspirations are managed appropriately so that trainees who are not able to obtain their chosen posts are still satisfied with the eventual outcome of their training. This may become more apparent when looking at the results of the cohort survey after 5 years in training, when trainees have been able to apply for grid specialist training.

\section{CONCLUSION}

In summary, this survey has provided a unique insight into the progress and aspiration of those doctors entering paediatric training. To have a strategy for a sustainable paediatric workforce there has to be a balance between providing high quality services and ensuring that paediatrics provides an attractive and rewarding career. This will require a balance between career aspirations and suitable working practices. We know that medical students enjoy their exposure to paediatrics and that many of them will consider paediatrics as a career. The current study has shown that while our trainees continue to enjoy paediatrics, even at a relatively early stage in their training programme, they are beginning to express some reservations around the likely future role of the consultant paediatrician and the availability of consultant posts. The RCPCH continues to recommend that services should be provided by trained doctors and the majority of our trainees aspire for consultant posts. After 3 years we are seeing an imbalance between trainees' aspirations for different types of consultant posts and the current number of paediatric consultant specialty posts. We will continue to review these issues as paediatricians progress through their training.

Contributors DS led this work although received very valuable contributions from all of the other identified authors. All authors have been involved in all of the following aspects: Substantial contributions to the conception or design of the work; or the acquisition, analysis, or interpretation of data for the work; drafting the work or revising it critically for important intellectual content; final approval of the version to be published; agreement to be accountable for all aspects of the work in 
ensuring that questions related to the accuracy or integrity of any part of the work are appropriately investigated and resolved.

\section{Competing interests None.}

Provenance and peer review Not commissioned; externally peer reviewed.

\section{REFERENCES}

1 British Paediatric Association. Paediatric medical staffing for the '90s. BPA, 1991.

2 Calman KC, Temple JG, Naysmith R, et al. Reforming higher specialist training in the United Kingdom - a step along the continuum of medical education. J Med Educ 1999:33:28-33.

3 Department of Health. The new deal on junior doctors' hours: the next stage. EL972; The Working Time Regulations 1998. SI 1998/No. 1833. London: The Stationery Office, 1997.

4 Department of Health. The European working time directive-UK notification of derogation for doctors in training. London: Department of Health, 2009.

5 DH, Scottish Executive, Welsh Assembly Government, Dept. of Health, Social Services and Public Safety. Modernising medical careers: the next steps-the future shape of foundation, specialist and general practice training programmes. London: The Stationery Office, 2004.

6 Donaldson L. Unfinished business: proposals for reform of the Senior House Officer Grade - a paper for consultation. London: Department of Health, 2002.
7 Temple J. Time for training: a review of the impact of the European working time directive on the quality of training. Medical Education England, 2010.

8 The Information Centre for Health and Social Care. NHS workforce: summary of staff in the NHS: results from September 2011 census. HSCIC, 2012.

9 RCPCH. Facing the future: a review of paediatric services. RCPCH, 2011.

10 RCPCH. Back to facing the future: an audit of acute paediatric service standards in this UK. RCPCH, 2013.

11 Turner G, Lambert TW, Goldacre MJ, et al. Career choices for paediatrics: national surveys of graduates of 1974-2002 from UK medical schools. Child Care Health Dev 2006;33:340-6

12 Thomas R. How do doctors choose their specialty: first love, arranged marriage or second time around? Clin Med 2008;8:4490-92.

13 Davidson J, Lambert T, Goldacre J. Career pathways and destinations 18 years on among doctors who qualified in the United Kingdom 1977; postal questionnaire survey. BMJ 1998;317:1425-8.

14 Ellin DJ, Parkhouse HS, Parkhouse J. Career preferences of doctors qualifying in the United Kingdom in 1983. Health Trends 1986;18:59-63.

15 Goldacre J, Laxton L, Lambert TW. Medical graduates' early career choices of speciality and their eventual specialty destinations: UK prospective cohort studies. BMJ 2010;340:3199-208.

16 British Medical Association. The cohort of 2006 medical graduates: first report June 2007. BMA, 2007. 